Poster Section

\title{
Effect of homeopathic treatment used in commercial boar semen diluent on sperm viability
}

\author{
Francisco Rafael Martins Soto ${ }^{1}$, Erlete Rosalina Vuaden ${ }^{2}$, \\ Cidéli de Paula Coelho ${ }^{3}$, Leoni Villano Bonamin ${ }^{4}$, Sergio Santos Azevedo ${ }^{5}$, \\ Nilson Roberti Benites ${ }^{3}$, Mariana Groke Marques ${ }^{3}$, \\ Flavia Regina Oliveira Barros ${ }^{3}$, Marcelo Demarchi Goissis ${ }^{3}$, \\ Maira Elena Ortiz D’Avila Assumpção ${ }^{3}$, José Antonio Visintin ${ }^{3}$
}

\author{
${ }^{1}$ Center for Sanitary Surveillance and Zoonoses Control “Tereza R. de Camargo”, Brazil \\ 2M Cassab- Animal Technology, Brazil \\ ${ }^{3}$ College of Veterinary Medicine and Animal Sciences, University of Sao Paulo, Brazil \\ ${ }^{4}$ Faculty of Veterinary Medicine, Paulista University, Brazil \\ 5Academic Unity of Veterinary Medicine University of Campina Grande, Brazil
}

\begin{abstract}
Background: It has been speculated that the homeopathic treatment of sperm cells in order to improve semen quality could be promising. However, few data is available and its use in spermatozoa requires investigation. It is well established that mitochondrial membrane potential is an important viability parameter of spermatozoa and it is intimately related to reproductive efficiency. In this manner, new technologies in order to improve the activity of sperm cells and, finally, the fecundity of swine herds are of extremely importance. Due to the lack of knowledge of homeopathic treatment effect on spermatozoa, the aim of the present study was to verify the effect of three different homeopathic treatments on viability of boar sperm cells.
\end{abstract}

Methods: semen samples were obtained from two sexually mature boars (18 mo of age). The boars were cross bred, with similar genetics of Pietrain versus Duroc, BP 450 progeny from a supplier company of similar reproductive performance animals. The animals were maintained in individual stalls, study conducted in Sao Paulo - Brazil. Three homeopathic treatments: Pulsatilla 6CH, Avena $6 \mathrm{CH}$ or both, compared to placebo treatment (sucrose), the homeopathic medicaments or the control were administrated as globules manipulated according Brazilian Homeopathic Pharmacology. Each globule weighted $30 \mathrm{mg}$ and contained sucrose as vehicle. One dose of two globules was added per $100 \mathrm{~mL}$ of diluted boar semen, which were chilled for 24 or 48 hours. All samples were labeled in codes in order to allow all laboratory analysis and evaluations being performed as a blind test. Data were tested for normality of residues and homogeneity of variances using the Guided Data Analysis software. Variables 
and interactions were analyzed by the PROC MIXED of the SAS package (SAS Institute Ins. Cary, NC). Adjusted least squares means (LSMEANS) of treatments were compared using the Tukey Test.

Results: The different treatments contributed to maintain acrossome integrity for prolonged periods of cooling over 48 hours. The use of Pulsatilla was effective in maintaining high sperm mitochondria activity up to 24 hours from harvesting (figures 1, 2 and 3).
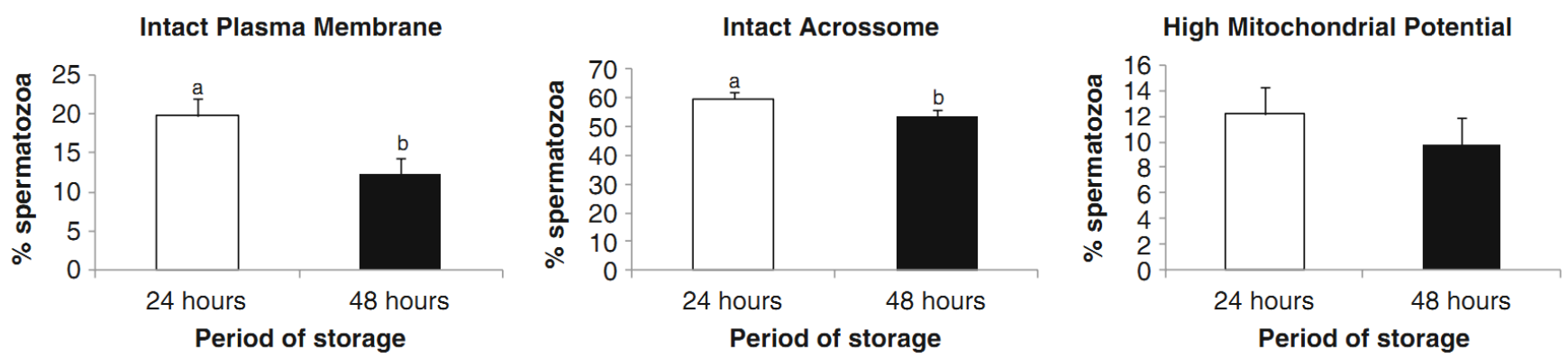

Figure 1. Effect of storage period (24 or $48 \mathrm{~h}$ ) on intact plasma membranes, intact acrossome, and high mitochondrial potential rates.
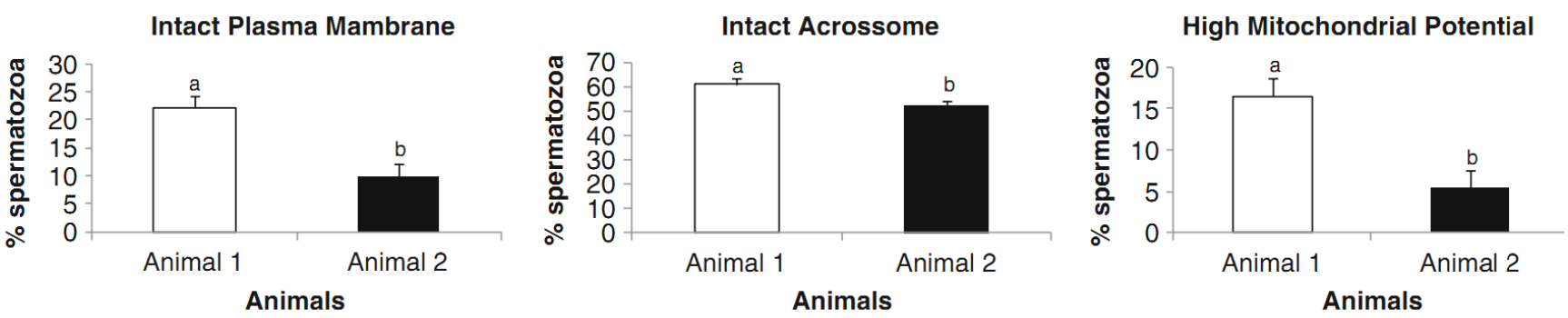

Figure 2. Effect of Animal on intact plasma membranes, intact acrossome, and high mitochondrial potential rates.
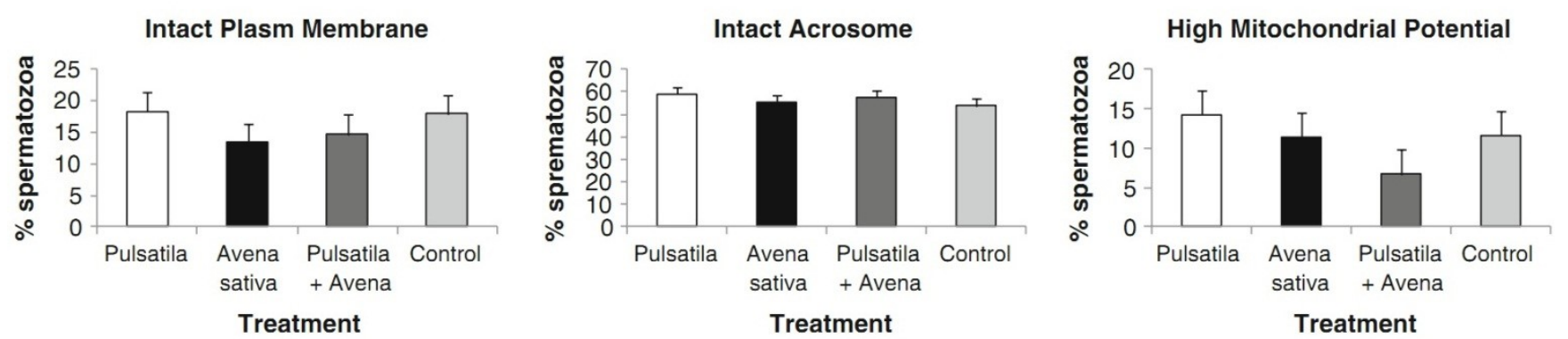

Figure 3. Effect of homeopathic (Pulsatila, Avena, Pulsatila +Avena) or control on intact plasma membrane, intact acrosome, and high mitochondrial potential rates.

Conclusion: Homeopathic medications can be used in artificial insemination in order to improve the quality of cooled and stored pig semen [1]. 
Keywords: homeopathy, swine semen, sperm viability.

\section{Reference}

[1] Soto, F. R. M.; Vuaden, E. R.; Coelho, C. P.; Bonamin, L. V.; Azevedo, S. S. A.; Benites, N. R.; Barros, F. R. O.; Goissis, M. D.; Assumpção, M. E. O. D.; Visintin, J. A.; Marques, M. G. Effects of the utilization of homeopathic elements in commercial diluent on swine sperm viability. In Vitro Cell.Dev.Biol.-Animal. 47:205-209, 2011.

\section{(c) EY-NC-ND Licensed to GIRI}

Support: authors declare that this study received no funding

Conflict of interest: authors declare there is no conflict of interest

Received: 01 June 2012; Revised: 09 August 2012; Published: 30 September 2012.

Correspondence author: Francisco Rafael Martins Soto, chicosoto34@gmail.com.

How to cite this article: Soto FRM, Vuaden ER, Coelho CP, Bonamin LV, Azevedo SS, Benites NR, Marques MG, Barros FRO, Goissis MD, Assumpção MEOD, Visintin JA. Effect of homeopathic treatment used in commercial boar semen diluent on sperm viability. Int J High Dilution Res [online]. 2012 [cited YYYY Month dd]; 11(40):174-176. Proceedings of the XXVI GIRI Symposium; 2012 Sep 20-22; Florence (Italy). GIRI; 2012; Available from: http://www.feg.unesp.br/ ojs/index.php/ijhdr/article/view/583/589 